\title{
Margaret McCartney: Patients and professionals: all in this together?
}

\author{
Margaret McCartney general practitioner, Glasgow
}

What does partnership mean? Together. On the same side. Working as one. At least, that's what it means to me, so the tone of some of the recent debate on patient empowerment has surprised me. Many articles in the medical press are telling doctors to get out of the driving seat—saying that we oppress patients, who need "emancipation."

Much of medicine is still grounded in paternalism; this is true. And it's true that services are often designed for the healthiest middle classes rather than for people with multimorbidity or who lack internet access or have poor literacy, for example.

Doctors are not the enemy, though. I want emancipation, too: I am working for the government rather than patients, and this system leaves me drained and distressed. It judges me on whether I give advice about obesity — which may well cause offence - to people who don't want it. ${ }^{1}$ I am paid if I find out whether people smoke, even if they attend about an entirely unrelated matter and my asking them distracts from this. And it's similar with screening: the original Scottish deal was to pay GPs to persuade more people to have bowel cancer screening. Only after protests was this changed to promote informed choice instead. ${ }^{2}$

We need a revolution where patients truly come first, not politicians, because if professionals and patients are not on the same side we are sunk. We've had too much division: primary care versus secondary care, managers versus doctors, nurses versus doctors. Much of this has arisen from political decisions, but, rather than patients and professionals uniting and challenging dogma, we've been divided.

Every day I fail to do things as well as I should. I don't spend enough time discussing this preventive strategy or that treatment. I don't spend enough time talking about what drugs we should stop or why an alternative treatment is wasting money. We struggle with cuts to our district nurses; our hospitals struggle with fewer beds. We struggle with a new load of cardiovascular preventive work that scarcely has enough supporting decision making tools, never mind the time to use them properly. We struggle with a lack of social care services. And we are all under-resourced to help our elderly, multimorbid populations to live and die well.

Doctors have often been accused of putting self interest before patient care, but I honestly believe that most doctors go into medicine because they want to do good. So I hope that the patient movement becomes the patient and healthcare professional movement and that, together, we can identify and demolish the obstacles to better care.

Competing interests: I have read and understood the BMJ policy on declaration of interests and declare the following interests: I'm an NHS GP partner, with income partly dependent on Quality and Outcomes Framework points. I'm a part time undergraduate tutor at the University of Glasgow. I've written two books and earn from broadcast and written freelance journalism. I'm an unpaid patron of Healthwatch. I make a monthly donation to Keep Our NHS Public. I'm a member of Medact. I'm occasionally paid for time, travel, and accommodation to give talks or have locum fees paid to allow me to give talks but never for any drug or public relations company. I was elected to the national council of the Royal College of General Practitioners in 2013 and am chair of its standing group on overdiagnosis. I have invested a small amount of money in a social enterprise, Who Made Your Pants?

The BMJs readers can buy Margaret's new book, Living with Dying, for $£ 7.99$ (RRP £11.99) including UK delivery from www.pinterandmartin. com with checkout code BMJ799.

Provenance and peer review: Commissioned; not externally peer reviewed.

Follow Margaret on Twitter, @mgtmccartney

1 Lewis $\mathrm{E}$. Why there's no point telling me to lose weight. BMJ 2015;350:g6845. McCartney M. This is not informed choice. 22 August 2013. http://margaretmccartney. com/2013/08/22/this-is-not-informed-choice/.

Cite this as: BMJ 2015;350:h1331

๑ BMJ Publishing Group Ltd 2015 